\title{
GERENCIAMENTO DE ESTOQUE E MONTAGEM DE CURVA ABC EM UM SUPERMERCADO VAREJISTA NO MUNICÍPIO DE OSVALDO CRUZ
}

\section{MANAGING INVENTORY AND BOW MOUNT ABC IN A SUPERMARKET RETAILER IN CRUZ OSVALDO MUNICIPALITY}

Letícia Batoqui Munhoz, Marlon Seolin Correa, Tamires Mazaro Candeias, Tayná Dos Santos Martins, Andréia de Menezes Olivo.

Universidade do Oeste Paulista - UNOESTE, Engenharia de Produção, Presidente Prudente, SP.

E-mail: mseolin@gmail.com

RESUMO - O estudo da gestão de estoque dos produtos, direcionado à análise da curva $A B C$ de estoque, pode apresentar alternativas para que os produtos se tornem mais competitivos e atraentes aos clientes. Percebe-se que os investimentos em itens de estoque que ficam parados por períodos de tempo muito longos retêm um alto investimento de capital das empresas. O presente estudo tem como objetivo analisar o gerenciamento de estoque do supermercado Bandeiras utilizando-se da Curva $A B C$, permitindo ao gestor identificar a representatividade de cada item no estoque, obtendo diferentes níveis de controle com base na importância de consumo de cada item. A metodologia empregada trata-se de uma pesquisa exploratória, descritiva e analítica, utilizando-se da pesquisa bibliográfica baseada em livros e artigos científicos sobre o tema, e de uma pesquisa de campo no supermercado varejista da cidade de Osvaldo Cruz-SP. Os resultados são apresentados através de gráficos, onde os produtos selecionados foram classificados pelo sistema da curva $A B C$.

Palavras-chave: Gestão de Estoque; Curva $A B C$; Competitividade; Organização; Gerenciamento.

ABSTRACT - The study of the stock of product management, aimed at the analysis of the $A B C$ curve stock may present alternatives to the products become more competitive and attractive to customers. It is noticed that investments in stock items that sit for long periods of time retain a high capital investment companies. This study aims to analyze the supermarket inventory management Flags using the curve $A B C$, allowing the manager to identify the representativeness of each item in inventory, achieving different levels of control based on the

Recebido em: $17 / 08 / 2016$ Revisado em: $18 / 08 / 2016$ Aprovado em: 22/08/2016 importance of consumption of each item. The methodology this is an exploratory, descriptive and analytical research, using the literature based on books and scientific articles on the subject, and a field survey in the retail supermarket in the city of Osvaldo Cruz-SP. The results are 
presented through graphs, where the selected products were classified by the $A B C$ curve system.

Keywords: Inventory Management; ABC Curve; Competitiveness; Organization; Management. 


\section{INTRODUÇÃO}

Com a alta competitividade do mercado as empresas têm buscado cada vez mais atingir uma vantagem competitiva em relação a seus concorrentes. A gestão de estoque, um dos setores vitais para uma organização, quando bem administrada deixa a companhia no nível em que se exige o mercado. Segundo Alécio e Rocha (2013) na maioria das organizações a eficácia na gestão do estoque é por vários motivos, essencial ao êxito das operações, um desses motivos é o volume de dinheiro representado pelo estoque, o outro é o impacto do estoque sobre as operações cotidianas de uma organização.

De acordo com Kotler e Armstrong, (2003, p. 336) "o varejo engloba todas as atividades envolvidas na venda de bens ou serviços diretamente a consumidores finais, para seu uso pessoal, e não empresarial". Os supermercados são o tipo de loja de varejo que tem a maior frequência de compradores, e a cada dia que passa, vem ocupando um papel da maior importância na vida dos consumidores, pois dispõem de uma grande variedade de produtos alimentícios, sejam eles perecíveis ou não, além de produtos de utilidades domésticas (GIMPEL, 1980).

No ramo supermercadista a logística do estoque é de extrema relevância por se tratar de um ativo, onde sua má gestão pode acarretar na falência da empresa, pelo fato de carecer um alto investimento, por isso se justifica o uso de métodos que possam assessorar no gerenciamento. Um mecanismo que contribui para a administração dos estoques é a curva $A B C$, um recurso que proporciona relevantes informações sobre o produto que possui maior ou menor giro, relacionados com o custo de obtenção.

Dessa forma, o presente trabalho se justifica pela necessidade do controle de estoque em um supermercado, de forma a avaliar sua gestão de estoques, utilizando a curva $A B C$ como ferramenta de auxílio na separação dos itens em classes, verificando os produtos com maiores relevância de custo.

\section{Gestão de Estoque}

Segundo Krajewski, Ritzman e Malhotra (2009) estoque é qualquer matéria prima, material, componente, ferramenta ou produto acabado que esteja guardado para utilização futura, onde quanto maior a diversidade de itens estocados mais complexo é o seu controle. Para Chiavenato (2014), a acumulação de estoques em níveis adequados é necessária para o funcionamento da maioria das organizações, de forma a vender com o mínimo de risco de paralisação, em contra partida, o estoque 
representa um enorme investimento financeiro que precisa ser controlado.

Para que as empresas controlem seus estoques, estas precisam de informações precisas já que sem elas as organizações podem cometer grandes erros quanto, a pedidos em excesso ou insuficientes, provocando a falta de estoque para determinado produto e excesso para outro. (KRAJEWSKI; RITZMAN; MALHOTRA, 2009). Assim o gerenciamento de estoque, surge para estabelecer os níveis de estoque adequado, a fim de determinar qual o volume necessário para cada item e para um determinado período, isto é, qual a periodicidade das compras e qual o giro do estoque (CHIAVENATO, 2014).

\section{A CURVA ABC}

O planejamento e controle de estoque tende a ser um ponto difícil de uma administração devido a maioria das empresas trabalharem com certa variedade de produtos, sendo alguns itens mais importantes para a organização do que outros, assim a classificação $A B C$ vem para auxiliar esse gerenciamento. (LOURENÇO; CASTILHO, 2006)

Dessa forma Pinheiro (2005) argumenta que a classificação $A B C$ consiste em auxiliar na identificação da representatividade financeira de cada item estocado e separá-los em três grupos, para que possam receber o devido tratamento, permitindo um controle seletivo do estoque.

De acordo com Slack, Chambers e Johnston (2009), a lei de Pareto é o princípio básico da curva $A B C$, onde uma pequena proporção, aproximadamente $20 \%$ de todos os tipos de produtos estocados representa uma grande proporção, em torno de $80 \%$ das vendas de uma operação.

Dentro dessa classificação os itens são separados em três classes diferentes, A-B e C:

- Itens classe A são aqueles $20 \%$ de itens de alto valor que representam cerca de $80 \%$ do valor total do estoque.

- Itens classes B são aqueles de valor médio, usualmente os seguintes $30 \%$ de itens que representam cerca de $10 \%$ do valor total.

- Itens classe $\mathrm{C}$ são aqueles itens de baixo valor que, apesar de compreender cerca de $50 \%$ do total de tipos de itens estocados, provavelmente representam somente cerca de $10 \%$ do valor total de itens estocados (SLACK; CHAMBERS; JOHNSTON, 2009, p.377).

Segundo Oliveira (2011) a construção da curva $A B C$ deve ser feita em três fases, elaborar a tabela, em seguida construir o gráfico e posteriormente a interpretação do gráfico, com identificação completa de percentuais, quantidades e faixa de valores dos itens envolvidos em cada classe.

$O$ gráfico da curva $A B C$ é de natureza crescente, onde a classe A representa os 
itens que requerem um tratamento preferencial em relação aos demais itens pertencentes a classes B e C, por possuírem uma maior representatividade financeira do estoque. (SLACK; CHAMBERS; JOHNSTON, 2009)

\section{METODOLOGIA}

A metodologia empregada trata-se de uma pesquisa exploratória, descritiva e analítica, que parte da pesquisa bibliográfica baseada em livros e artigos científicos sobre o tema, e de uma pesquisa de campo em um supermercado varejista da cidade de Osvaldo Cruz, com o objetivo de desenvolver o gerenciamento do estoque e a classificação na curva $A B C$ dos seus materiais armazenados.

Após o estudo realizado e os dados obtidos estes foram compilados e subdivididos em tabelas classificados por categorias de produtos como: panifícios, enlatados, temperos, molhos, doces, produtos de cesta básica, entre outras e algumas das categorias mais representativas foram estudadas.
Com o auxílio das tabelas foi possível a montagem gráfica da curva $A B C$ das categorias de produtos mais representativos, possibilitando uma melhor compreensão de quais produtos dentro de cada categoria seriam da classe $A, B$ e $C$ e quais possuem mais valor dentro do estoque e precisam de atenção no gerenciamento.

\section{RESULTADOS}

Com os dados fornecidos pelo supermercado foi possível observar os itens com maior importância e relevância do estabelecimento. Os produtos foram analisados em relação ao custo e a quantidade vendida, a fim de resultarem nos que representam maior valor no estoque e devem ser gerenciados por representarem a maior parte do faturamento. Para definição de tais produtos foi construído o gráfico de Histograma representado na Figura 1 que utiliza a distribuição de Gauss como ajuste da curva normal para selecionar os itens mais representativos pelo seu posicionamento centralizado. 
HISTOGRAMA

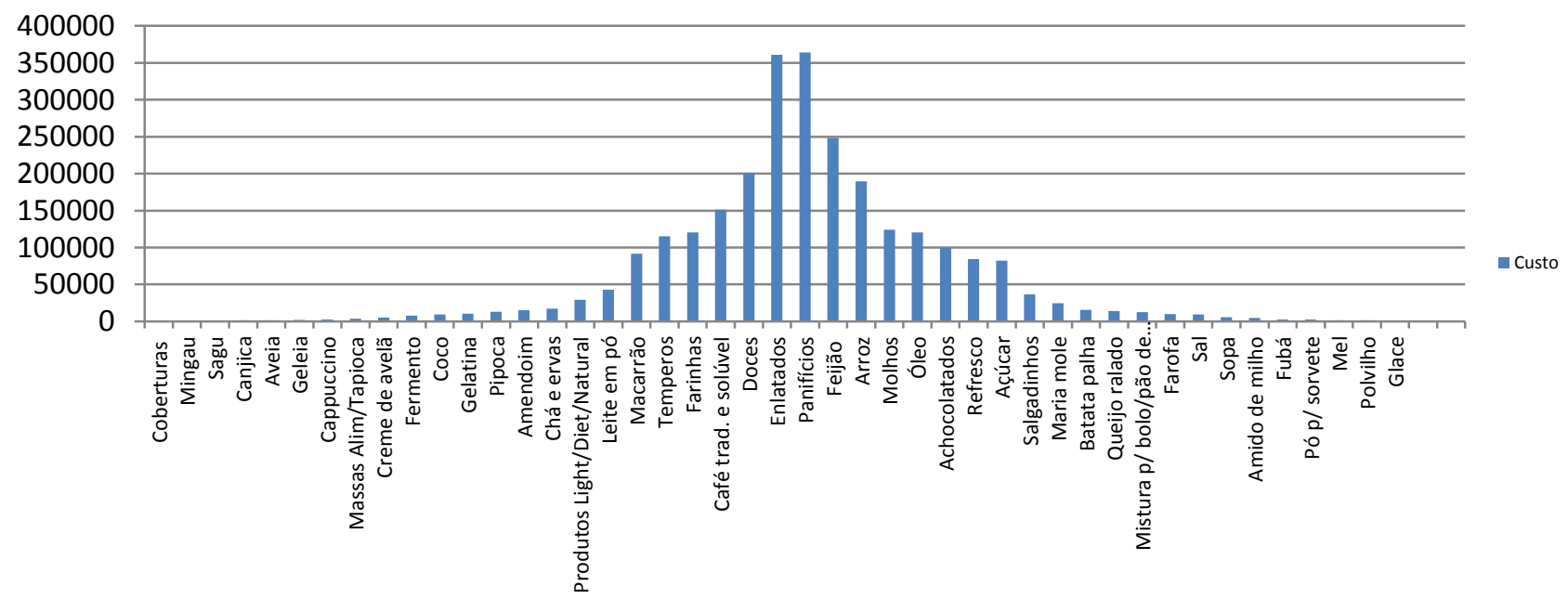

Figura 01. Histograma dos produtos estocados no supermercado pela relação de seus custos. Fonte: Autoria própria.

Os panifícios, enlatados, feijão, doces, arroz, café, molhos, farinhas e óleos foram os produtos mais representativos, portanto deve-se ter um controle efetivo sobre os mesmos para que não faltem. Para melhor compreensão da importância desses itens dentro do estoque foram analisados os panifícios, enlatados, doces, molhos, temperos e os produtos que constituem uma cesta básica como o arroz, feijão, óleo e farinha a fim de permitir a identificação dos produtos mais relevantes.

Para possibilitar a identificação desses produtos foi criada a Figura 2 que apresenta quais dessas famílias de alimentos são as mais significantes de acordo com sua classificação, auxiliando dessa forma na tomada de decisões para o estoque do estabelecimento.

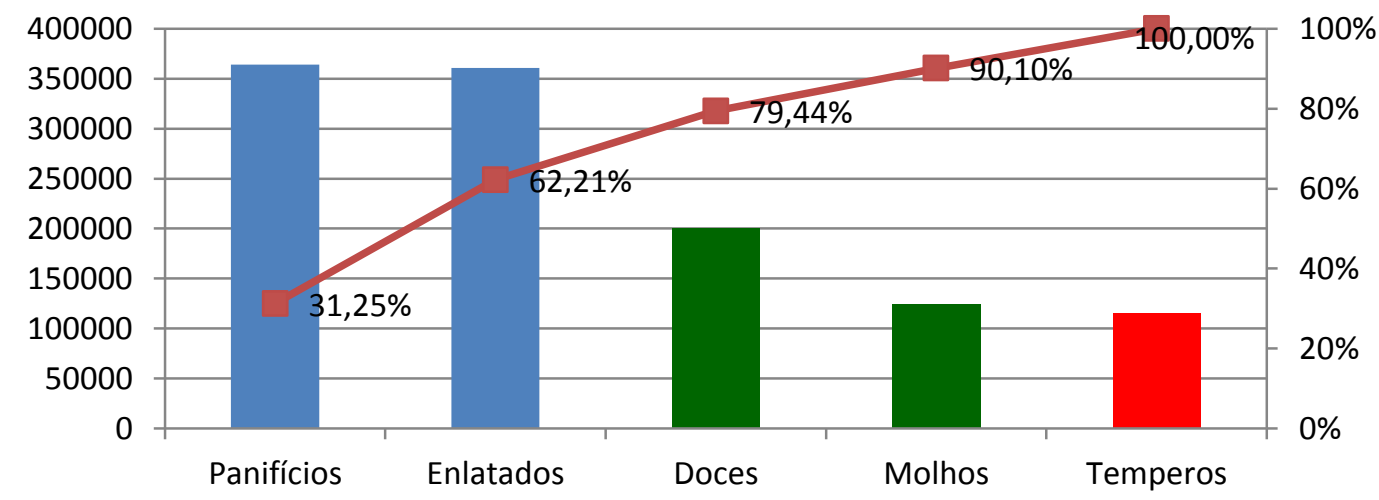

Figura 02. Gráfico da classificação $A B C$ das famílias dos produtos mais significativos. Fonte: Autoria própria.

É possível observar que a classe A é composta pelos panifícios que são os biscoitos, pães, bolos e torradas, juntamente com os enlatados como o óleo, leite 
condensado, leite em pó, sardinha, creme de leite, azeitona, azeite, milho verde, atum, sustagem, palmito, ervilha, seleta, chantilly, caldas, leite de coco, champignon, salsicha, feijoada, picles, cogumelo, almôndegas e legumes e gengibre em conserva. Esses são responsáveis por $62,21 \%$ do valor do estoque sendo os principais itens e que dessa forma necessitam de alta prioridade, foco de atenção do gestor, pois são alimentos com grande importância econômica e necessitam de abastecimento frequente para atender a sua grande demanda e para isso precisam de grande espaço na área de estocagem.

A classe $B$ tem uma representatividade de $27,89 \%$ no valor do estoque e compreende os itens que ainda são considerados economicamente preciosos, logo após os itens de categoria $A$, e que recebem cuidados medianos. Essa classe é composta pelos doces que são os chocolates, bombons, balas, chicletes, paçocas, goiabadas, rosquinhas, pé de moleque, pirulitos, torrones, marshmallow, arroz caramelizado, marmeladas, cocadas e doces em geral e pelos molhos como de tomate, maionese, extrato de tomate, catchup, shoyu, molho de pimenta, mostarda, polpa de tomate, molho de salada, molho madeira, patê, molho yakissoba, molho quatro queijos, molho para churrasco, molho inglês, molho de alho, molho para lanches, molho branco, molho cheddar, molho verde, molho oriental, molho de pipoca, molho de vinagre, molho para carneiro e molho árabe.

A classe $C$ é constituída pelos temperos que são os caldos, sazon, vinagres, alhos, fermentos, pimentas, temperos para carne, sal, colorífico, temperos sem pimenta, orégano, tempero de alho e sal, tempero para frango, tempero completo, tempero para feijão, chimichurri, cravo da índia, canela, tempero para assados, tempero para churrasco, tempero para massas, tempero para arroz, tempero para salada, tempero baiano, tempero para legumes, tempero de louro, cominho, açafrão, alcapara, tempero nordestino, ervas finas, tempero para aves, cheiro verde, tempero mineiro, tempero gaúcho, tempero para galinha caipira, coentro, curry, tempero para peixe, noz moscada, gergelim, cebolinha, tempero para camarão, manjericão, wasaby, tempero oriental e tempero italiano,

Os temperos representam no estoque um valor de apenas 9,90\% dos custos, isto é são mercadorias pouco solicitadas, contendo pouca relevância no faturamento da empresa e assim necessitando de uma distribuição menos frequente por serem produtos com demanda menor bem como necessitam de menos espaço no estoque e seu impacto econômico é menor em caso de falta. Dessa forma cada classe dos itens pode ter uma distribuição diferente, os itens A podem receber mais distribuições e ter altos níveis 
de disponibilidade, enquanto os itens C podem ser distribuídos com níveis de estoque menores do que os praticados para itens A e os Itens da classe B podem ter uma estratégia intermediária de distribuição.

Com o intuito de tornar mais compreensível as causas e consequências da classificação de produtos baseados no Princípio de Pareto, foi feita uma simulação também dos principais produtos que podem compor uma cesta básica por serem produtos com grande demando como visto na Figura 1. Selecionada as categorias desses produtos, foi possível realizar a montagem da Curva $A B C$ baseada no custo real de cada produto adquirido pelo supermercado, bem como sua frequência acumulada. Observando a Figura 6, pode se identificar os produtos que se enquadram em cada uma das três classes da Curva ABC.

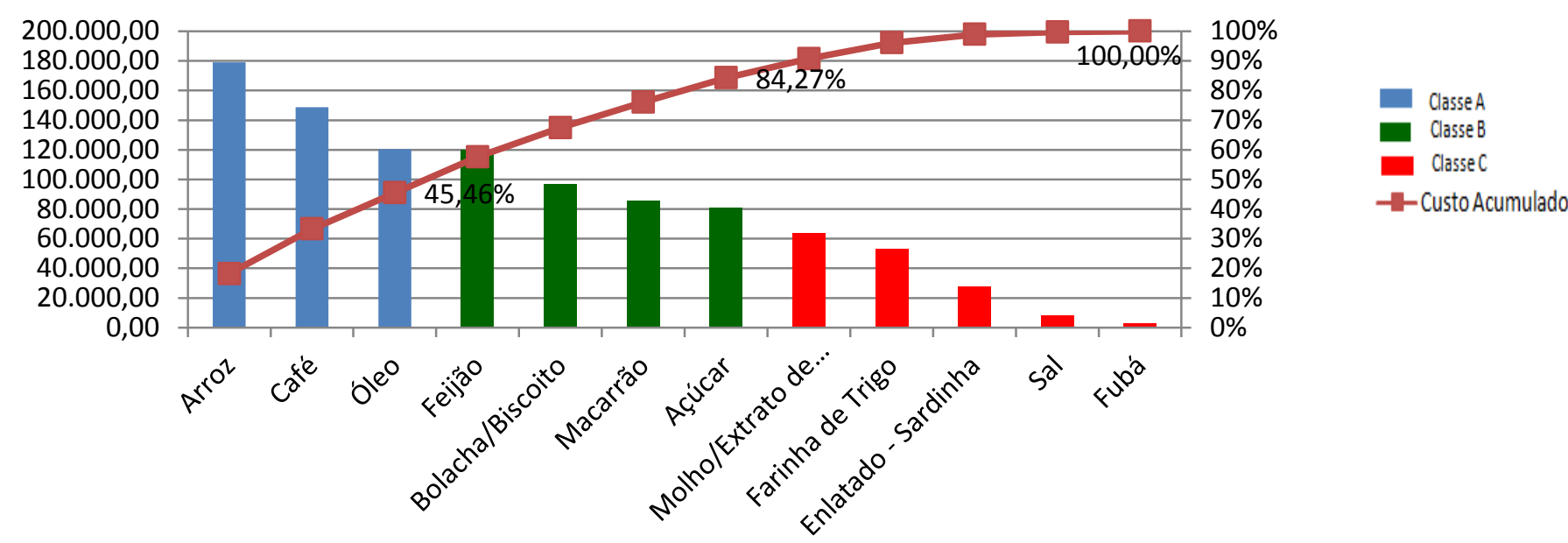

Figura 06. Gráfico da classificação $A B C$ dos produtos que compõe uma cesta básica.

A Classe A compreende os itens que correspondem a $45,46 \%$ do valor total investido em estoque e $25 \%$ dos itens selecionados que compõem uma cesta básica, sendo representada pelo arroz, café e óleo. Percebe-se que são produtos periodicamente utilizados e procurados pelos brasileiros, por isso nunca podem faltar nas prateleiras do supermercado. Tendo em vista sua alta representatividade no consumo e consequentemente no estoque, os produtos da Classe $A$, necessitam de monitoramentos constantes, pois apesar de representarem uma pequena porcentagem dos itens selecionados, respondem pelo maior capital investido em termos de estoque, logo qualquer modificação indevida na aquisição e armazenamento desses produtos terá um impacto considerável. O ideal é verificar como está a saída desses produtos e planejar a reposição com bastante antecedência.

A Classe B é composta pelo feijão, bolachas/biscoitos, macarrão e açúcar e são considerados itens intermediários entre as classes A e $C$, respondem em média por cerca de $33 \%$ dos itens selecionados e $38,80 \%$ do 
valor monetário do estoque. Os produtos dessa classe podem ser inspecionados por um sistema de controle de estoque intermediário pelo fato de terem um médio giro de compras, mas ainda assim, possuem uma boa margem de contribuição.

Os produtos da classe C são o molho/extrato de tomate, farinha de trigo, sardinha enlatada, sal e fubá. Esses produtos representam $15,73 \%$ dos custos totais e são $41,66 \%$ dos itens de uma cesta básica, embora represente a maioria dos produtos da cesta básica eles são os menos demandados e consequentemente possuem menos representatividade nos lucros. Dessa forma não possuem necessidade de grandes quantidades em estoque em comparação com as outras duas classes já que seu giro é menor e grandes aquisições dos mesmos poderiam gerar desperdícios e não favoreceria o aumento da lucratividade.

\section{CONSIDERAÇÕES FINAIS}

Após todas as análises feitas com os produtos das principais famílias que foram retiradas pela observação dentro do histograma sobre sua representatividade no mercado estudado, foi possível classificar os produtos que mais demandam atenção dos gestores do mercado em relação a manter ou não estoques de determinados produtos com base na classificação da curva $A B C$.
As famílias dos principais segmentos de produtos retiradas do histograma foram dos paníficios, enlatados, doces, molhos, temperos e a cesta básica. Com o uso da curva $A B C$ foi possível visualizar quais itens detém uma maior significância em relação a custo e procura.

Assim os panifícios e enlatados foram os produtos que apresentaram ter um maior destaque com $62,21 \%$ do custo do estoque, se enquadrando na classe A dos produtos, enquanto que os doces e molhos tiveram $27,89 \%$ de representatividade no valor do estoque sendo classificados na classe $B$ e os temperos representaram $9,90 \%$ do valor dos produtos estocados e por fim, na cesta básica o arroz, café e óleo tiveram $45,46 \%$ do valor total do estoque, sendo os produtos a receberem maiores cuidados.

Assim, esses itens que pertencem à classe $A$, são produtos indispensáveis que precisam ser acompanhados para que possa haver sua reposição à medida que forem saindo, portanto necessitam que na distribuição física do estoque sua ocupação de espaço seja maior, já que sua ausência pode comprometer o faturamento do mercado. Quanto aos produtos das classes B e $C$ dos grupos explorados, são aqueles cuja demanda é pouca, e apesar de entrarem para o mix do mercado não demandam de grandes quantidades estocadas como a classe A. 


\section{REFERÊNCIAS}

ALÉCIO, P.L.C.; ROCHA, R.P. Análise da Gestão de estoques: aplicando a ferramenta da curva $A B C$ no estoque de um supermercado. 2013. Disponível em: <http://www.fecilcam.br/anais/vii_eepa/dat a/uploads/artigos/1-03.pdf.>. Acesso em: 17 maio 2015.

CHIAVENATO, I. Gestão de materiais: uma abordagem introdutória. 3. ed. Barueri, SP: Manole, 2014. Disponível em: <http://unoeste.bv3.digitalpages.com.br/use rs/publications/9788520437995>. Acesso em: 15 maio 2015.

GIMPEL, L. J. Administração de empresas varejistas no Brasil. São Paulo: Atlas, 1980.

KOTLER, F.; ARMSTRONG, G. Princípios de marketing. 9. ed. São Paulo: Pearson, 2003. Disponível em: $<$ http://unoeste.bv3.digitalpages.com.br/use rs/publications/9788587918192/pages/_1>. Acesso em: 13 maio 2015.

KRAJEWSKI, L.; RITSMAN, L.; MALHOTRA, M. Administração de produção e operações. 8. ed. São Paulo: Pearson, 2009. Disponível em: <http://unoeste.bv3.digitalpages.com.br/use rs/publications/9788576051725>. Acesso em: 15 maio 2015.

LOURENÇO, K.G; CASTILHO, V. Classificação $A B C$ dos materiais: uma ferramenta gerencial de custos em enfermagem. Revista Brasileira de Enfermagem, v.59, n.1, p.52-5, jan/fev.2006. Disponível em: <http://www.scielo.br/pdf/reben/v59n1/a10 v59n1.pdf>. Acesso em: 15 maio 2015.

OLIVEIRA, C.M. Curva $A B C$ na Gestão de Estoque. 2011. Disponível em: <http://www.unisalesiano.edu.br/simposio2 011/publicado/artigo0075.pdf.>. Acesso em: 16 maio 2015.

PINHEIRO, A.C.M. Gerenciamento de Estoque Farmacêutico. Revista Eletrônica de
Contabilidade, v.1, n.3, mar/maio 2005. Disponível em: <http://cascavel.ufsm.br/revistas/ojs2.2.2/index.php/contabilidade/article/view/8 0/3951>. Acesso em: 15 maio 2015. 